\title{
Flyktingskap, ett handikapp
}

NORMA MONTESINO

\begin{abstract}
I slutet av 1940-talet beslutade Sverige att ta emot ett begränsat antal icke-arbetsföra flyktingar. Denna artikel ger den internationella och nationella bakgrunden till detta beslut, beslut som gav upphov till framväxten av en specifik flyktingverksamhet inom socialtjänsten. Artikelns syfte är att med hjälp av ett historiskt perspektiv förstå bakgrunden till socialtjänstens arbete med flyktingar $i$ Sverige. ${ }^{l}$
\end{abstract}

\section{Bakgrund}

Ett internationellt samarbete växte fram efter 1945 för att kunna hantera den svåra flyktingsituationen i Europa (Holborn 1975). Samarbetet syftade till att underlätta för flyktingarna att återvända till sina hemländer (repatrieringen) eller hjälpa dem att emigrera och etablera sig i ett tredje land; bl.a. organiserades det en omfattande transkontinental migration till bl.a. Canada, USA och Latinamerika (ibid.). Till en början förväntades att emigration och repatriering skulle räcka till för att alla flyktingar skulle återfå ett medborgarskap, men i slutet av 1940-talet fick de internationella

Norma Montesino, universitetslektor, Institutionen för vårdvetenskap och socialt arbete, Växjö universitet organisationerna erkänna att dessa förhoppningar inte infriats (Holborn 1975, Pinegar 1960, Proudfoot 1956, van Heuven Goedhart 1953, Woodbridge 1950). I juni 1949 fanns det fortfarande ca 175000 flyktingar kvar i de internationella uppsamlingslägren runt om i Europa. Gemensamt för alla dessa individer var att de inte betraktades som arbetsföra (Holborn 1975, Proudfoot 1956, van Heuven Goedhart 1953, m.fl.). För att hantera denna situation åtog sig en rad länder bl.a. Sverige att ta emot flyktingar ur denna grupp. De kvoter flyktingar

1 Artikeln ingår i ett tvärtvetenskapligt projekt finansierat av Vetenskapsrådet (VR) : „Föreställningar kring arbetsförmåga och ohälsa. Icke arbetsföra flyktingar i Sverige 1950-2005 « Norma Montesino (socialt arbete) och Malin Thor (historia). 
som togs emot i Sverige ledde till konkreta åtgärder inom ramen för det sociala arbetets praktik, som grundades på det internationella samfundets definition av dessa flyktingar som handikappade.

Artikelns syfte är att i ett historiskt perspektiv förstå framväxten och etableringen av en särskild flyktingkategori, "handikappade flyktingar", som kom att forma socialtjänstens praktik kring flyktingar. Artikelns första avsnitt presenterar de teoretiska och metodologiska utgångspunkterna i form av en kronologisk rekonstruktion av de sammanhang där flyktingproblematiken växte fram. Det andra avsnittet beskriver den internationella kontexten i vilka flyktingproblematiken definierades. Tredje avsnittet beskriver de särskilda flyktingkvoter som Sverige började ta emot år 1950. Mitt övergripande syfte är att spåra de sammanhang i vilka flyktingar differentierades som en särskild målgrupp för myndigheternas insatser.

\section{Teoretiska och metodologiska ansatser}

Andra världskriget gav upphov till en utveckling i vilken »flyktingen" etablerades som en särskild kategori och "flyktingfrågan" differentierades som en specifik problematik (Malkki 1995). Frågan är hur specifika de egenskaper är som flyktingkategorin tilldelas och vad det är som gör "flyktingfrågan" till ett särskilt område för myndighetsintervention. För att förstå hur flyktingkategorin konstruerades och i vilka sammanhang interventionen blev en konkret praktik används ett historiskt institutionellt perspektiv (Immergut 1992, Lecours 2005).

Den historiska institutionalismen bygger sin analys på två spår: Ett som söker rekonstruera institutionernas ursprung och utveckling. Och ett som söker förstå de involverade aktörernas identiteter och handlingar. Det förstnämnda berör utvecklingen över tiden och fokuserar på institutionens uppkomst, kontinuitet och förändring medan det senare behandlar aktörerna och deras handlingsmöjligheter. Ett intressant begrepp i denna teoribildning är »critical junctures» som används för att förklara institutionell förändring. "Critical junctures« representerar de mest kreativa momenten i en institutions historia. Det handlar om omskakande händelser som förändrar förutsättningarna för det institutionella arbetet. Denna förändring kan beskrivas som paradigmatisk eftersom det förändrar institutionens givna ramar och därmed skapar nya förutsättningar för det institutionella arbetet. Dessa nya förutsättningar blir vägledande under en längre tid. Utifrån denna teoribildning framstår aktörers handlingsmöjligheter som begränsade eftersom de sker i en given institutionell ram: "path dependence» (Lecours 2005). Ett historiskt institutionalistiskt perspektiv sätter politikernas beslut eller/och tjänstemäns handlingar i sin tids och rums sammanhang och möjliggör mindre normativa förhållningssätt i analysen av aktörernas handlingar.

Flyktingmottagningen representerar en komplex problematik, som i grund och botten handlar om vilka kriterier som ska gälla när nya medlemmar ska räknas in i den egna organisationen. Artikelns studie- 
objekt avgränsas till de formativa moment ("critical junctures") i den svenska flyktingmottagningens framväxt. Frågorna som ska besvaras handlar om de sammanhang i vilka flyktingkategorin uppstod samt vilken typ av problem som då började förknippas med den s.k. flyktingfrågan.

Tilly hävdar att det finns en grundläggande logik som styr organisationer (Tilly 1998). När nya grupper/individer ska inkluderas i en organisation hanteras de utifrån etablerade och redan befintliga kategorier. Myndigheternas strategier för att hantera dessa grupper eller individer utgår från en generell mall som innefattar såväl inkluderande som exkluderande praktiker. I det internationella sammanhanget var det i första hand utanförskap i relation till nationalstaten som legitimerade konstruktionen av en särskild flyktingkategori. Nationalstaten utgör den givna institutionella ramen utifrån vilken föreställningarna kring flyktingskap konstruerades.

Flyktingkategorin konstruerades i ett internationellt sammanhang utifrån etablerade föreställningar om tillhörighet och utanförskap. Konstruktionen av flyktingkategorin är ett fenomen som tydligt speglar vissa grundläggande drag i moderniseringsprocessen. I detta fall är det differentieringsbegreppet som hjälper oss att förstå de processer i vilka flyktingkategorin fick olika innebörder. När flyktingen inkluderas i nationalstatens organisation inordnas han/ hon i de föreställningar och kategorier som finns etablerade inom denna organisation (Tilly 2005).

Under de senaste åren har tidigare forskning kring flyktingproblematikens hantering reviderats. Det handlar om forskning som nyanserar och/eller ifrågasätter förskönade berättelser kring segrarmaktens hantering av flyktingssituationen. ${ }^{2}$ Särskilt intressanta i detta sammanhang är de studier som fokuserar på de internationella flyktinglägren och de möjligheter som dessa slutna institutioner skapade för att hantera flyktingproblematiken (se till exempel Grossman 2002, Malkki 1995 \& 1996, Slatt 2001, Weindling 2006, Zalashik \& Davidovitch 2006). En grundlig genomgång av såväl tidigare som idag etablerad forskning kring flyktingar ("refugee studies") presenteras av antropologen Liisa Malkki (1992 \& 1995). Hennes kritiska granskning identifierar vissa antaganden som tas för givna $i$ både gemene mans föreställningar och den vetenskapliga diskursen kring flyktingar och flyktingskap. Till dessa självklarheter hör territoriell anknytning och nationell identitet. En ytterligare dimension i denna historia handlar om de konkreta åtgärder som växte fram kring flyktingarna på nationell nivå. Dessa åtgärder uppfattas i detta sammanhang som en del av de etablerade socialpolitiska lösningar som bygger på uppdelningen mellan de som ska hjälpas och de som skall stå för sin egen försörjning.

För att identifiera dessa processer använder jag en rad olika källor, dokument som behandlar de internationella sammanhang i vilka flyktingproblematiken definierades. Flera av dessa är beskrivande studier som behandlar Förenta Nationernas och andra internationella organisatio-

2 Till denna forskning hör den svenska studien "Blind fläck: minne och glömska kring svenska Röda Korsets hjälpinsats i nazityskland: 1945 (Lomfors 2005). 
ners flyktingverksamhet medan andra mer akademiska studier fokuserar på efterkrigstidens flyktingproblematik. För att få fram det svenska sammanhanget används i huvudsak dokument hämtade från Medicinalstyrelsens, Statens utlänningskommissions och Socialstyrelsens arkiv men även artiklar publicerade i Sociala Meddelanden (1912-1967) och Socialnytt (1968-1990). De båda tidskrifterna gavs ut av Socialstyrelsen och behandlade aktuella sociala frågor och informerade om lagändringar och andra beslut. Med hjälp av detta material söker jag förstå konstruktionen av flyktingkategorin och de processer som styrde inlemmandet av "flyktingar" i nationalstatens organisation. Fokus i min analys bygger på de internationella och nationella sammanhang i vilka dessa processer ägde rum.

\section{Det internationella sammanhanget}

De människor som flydde från förföljelse under andra världskriget kom att inordnas i en ny kategori och deras situation kom att, i första hand, betraktas som ett problem att hantera på internationell nivå. På nationell nivå kunde deras situation likställas med ett problem som de nationella myndigheterna hade brottas med sedan lång tid tillbaka: problemet med fattiga människor utan territoriell anknytning, den s.k. lösdriverifrågan. Detta problem hade redan under 1800-talet gett upphov till visst internationellt samarbete i form av bilaterala avtal, som stadgade att de utlänningar som inte fick vistas i ett land skulle utvisas till det land de kom ifrån. ${ }^{3}$ Så var inte fallet med flyktingarna efter kriget 1939-1945, eftersom det ofta inte fanns ett land att skicka dem tillbaka till. De problem som flyktingarna representerade kunde inte lösas med hjälp av tidigare avtal. Flyktingarna hade förlorat sitt medborgarskap. Det fanns inte någon lagstiftning som reglerade deras status och inga lagar som gällde deras situation. Utan medborgarskap saknade de den nationella tillhörigheten i en tid då nationella gemenskaper betraktades som naturliga.

Flyktingarna, menar Hannah Arendt (1966), representerade något särskilt hotfullt eftersom de befann sig utanför alla former av gemenskap som förknippades med en civiliserad värld.

"The danger in the existence of such people is twofold: first and more obviously, their ever-increasing numbers threaten our political life, our human artifice, the world which is the result of our common and co-ordinated effort in much the same, perhaps even more terrifying, way as the wild elements of nature once threatened the existence of man-made cities and countrysides. Deadly danger to civilization is no longer likely to come from without... The danger is that a global, universally interrelated civilization may produce barbarians from its own midst

3 Sverige ingick överenskommelser om utlämning av misstänkta förbrytare till deras hemländer: 1844 (med Belgien), 1852 (Hamburg), 1854 (Nederländerna), 1860 (Förenta Staterna) och 1863 (Portugal). Ytterligare överenskommelser gjordes med Ryssland angående återsändande av lösdrivare, tiggare och förbrytare (Nauman 1866). 
by forcing millions of people into conditions which, despite all appearances, are the conditions of savages". (Arendt 1966:302)

Vad Arendt identifierar är flyktingskapens existentiella grunder: det totala främlingskapet. Ett tillstånd som ifrågasätter en ordning som tas för given, den civiliserade ordningen. Utifrån denna utgångspunkt framstod flyktingar först och främst som stående utanför den givna gemenskapen som representerades av nationalstaten. Den som saknade territoriell tillhörighet fanns inte i den nationella befolkningsstatistiken, en icke befintlig person, i praktiken en ren polisiär angelägenhet (Arendt 1966). Såsom icke befintliga eller inte inkluderade i nationalstatens ordning beskrevs flyktingarna som en överskottsbefolkning, "a surplus population" (Holborn 1975, van Heuven Goedhart 1953, Woodbridge 1950).

Under andra hälften av 1940-talet växte det fram ett internationellt samarbete för att hantera de olika problem som kriget lämnade efter sig, flyktingar var en av dem (Holborn 1975). "Flykting" var en kategori som, innan andra världskriget, användes för klart avgränsade grupper såsom armenierna (som tvingades bort från Turkiet) eller rys-

4 Den första internationella organisationen som skapades inom FN:s regi var United Nations Relief and Rehabilitation Administration, UNNRA. Organisationens huvuduppgift handlade om återuppbyggnadsarbetet efter krigets slut. I UNNRA:s arbete ingick även att arbeta fram åtgärder för att lösa flyktingproblematiken. År 1947 skapades en särskild flyktingorganisation IRO (International Refugee Organisation), också inom Förenta nationernas regi (Holborn 1975, Thor 2007). sarna före och efter den ryska revolutionen (Holborn 1975, Malkii 1995, Proudfoot 1956, Woodbridge 1950). I slutet av andra världskriget började kategorin "flykting" att få en allmän mening i internationell rätt som refererade till de individer som saknade anknytning till nationalstaten. I dessa sammanhang identifierades flykting som en särskild kategori migranter. Till skillnad från andra migranter, menade de juridiska experterna, saknade flyktingarna ett legalt skydd eftersom det inte fanns en stat som hade ett juridiskt ansvar för dem (van Heuven Goedhart 1953).

Flyktingarna representerade något nytt som frambringade en omformulering av lagstiftningen. Den nya definitionen av flyktingkategorin utarbetades i relation till det som betraktades som naturligt och normalt: att vara medborgare. Utifrån denna föreställning om normalitet representerade flyktingskap en avvikelse. Denna första egenskap som tilldelades kategorin flykting relaterade då till en avvikelse i relation till lagen.

FN:s flyktingkommissarie beskrev flyktingens situation i följande termer.

"Laws concerning aliens are made with the conception of the normal, the protected alien in minds of the law-giver. It follows that the refugee, in whose case this protection is missing, suffers from a number of legal disabilities" (van Heuven Goedhart 1953:284)

Flyktingen definierades i termer av en brist eller frånvaro av det som "normala» individer (dvs. medborgarna) hade eller snarare var. De åtgärder som skapades hade som syfte att ge flyktingarna ett medborgar- 
skap, en territoriell tillhörighet, en ersättning för det som förlorats, det som beskrevs som "legal disabilities". "... the lack of citizenship presents some disability which requires surmounting (van Heuven Goedhart 1953 s. 304).

De första åtgärderna för att lösa flyktingfrågan inriktades på att återföra flyktingen tillbaka till det som betraktades som en normal situation.

"...to find an opportunity to start a new life, to become a normal member of a community, in the long run even a citizen of a new country" (van Heuven Goedhart s. 303)

De första konkreta åtgärderna var den storskaliga emigration och repatriering av flyktingar som genomfördes under 1940-talets andra hälft (Holborn 1975, Stoessinger 1956, etc.). Dessa åtgärder utgör ännu idag det internationella samfundets huvudåtgärder för att reglera denna specifika form av rörlighet.

Emigration och repatriering av flyktingar var omfattande, men det visade sig otillräckligt för att lösa flyktingproblemet. I slutet av 1940-talet erkändes det officiellt att repatrieringen och migration inte kunde lösa flyktingfrågan (se bl.a. Holborn 1975, Stoessinger 1956, Vernant 1953). De traditionella immigrationsländerna (Australien, Canada, USA, etc.) hade liksom andra länder infört en selektiv flyktingpolitik (Bashford 2005, Holborn 1975, Stoessinger 1956, etc.). De sökte högkvalificerad arbetskraft, dvs. unga utbildade människor med god hälsa (särskilt män). Urvalet skedde utifrån olika kriterier som förutom hälsosituationen relaterade till ålder, etnisk (ras på den tiden) och/eller nationell tillhörighet. I detta sammanhang prioriterades nordeuropéer, först och främst baltiska flyktingar (Stoessinger 1956). Vissa länder uttalade öppet att judar skulle sorteras bort t.ex. Chile, Brasilien och Argentina (ibid.). Andra länder sorterade utifrån tidigare medborgarskap: tyska judar kunde väljas medan östeuropeiska judar sorterades bort (ibid.). Mottagarländerna krävde ofta ett hälsointyg som utfärdades av läkare på flyktingläger (Weindling 2006).

Gränsen mellan frisk och sjuk, arbetsför och icke arbetsför legitimerades först och främst på medicinska grunder (Montesino 2007). ${ }^{5}$ Men kriterierna för att dra en gräns hämtades också från andra fält. Hälsostatus, familjesituation, kön och ålder var vanliga kriterier i bedömningen av arbetskapacitet, familjer med flera barn eller med en eller flera äldre medlemmar betraktades till exempel som icke-arbetsföra. Denna selektiva politik lämnade kvar många flyktingar i uppsamlingslägren. Dessa flyktingar var de som, av olika skäl, betraktades som oförmögna att arbeta och /eller en potentiell ekonomisk börda för de länder som skulle kunna ta emot dem.

"The proportion of low-skilled and aged refugees, and those in poor physical condition, has considerably increased in Europe..." (van Heuven Goedhart 1953s. 317)

De internationella myndigheterna differentierade dessa flyktingar som the hard core

5 R A Medicinalstyrelsen. Flyktingsjukvårdsarkiv FI:99 \& FI 104, sjukjournaler. FII: 2-4 Speciell flyktingsjukvård. 
or difficult cases or residual cases" (se bl. a. Stoessinger 1950, van Heuven Goedhart 1953). Juridiska kriterier hade stått till grund för definitionen av flykting som avvikande. "The hard core" representerade en problematik som inte enbart handlade om juridisk status. För att särskilja denna flyktinggrupp användes medicinska och sociala kriterier, kriterier som sammanfattades i kategorin handikapp. ${ }^{6}$

Kategorin handikapp hade börjat användas under andra världskriget i relation till krigsskadade soldater och utvidgades till att även omfatta andra grupper (Kerz et al. 1995). Användning av detta begrepp representerar ett nytt förhållningssätt i relation till arbetskapacitet. En förändring som byggde på etableringen av nya föreställningar kring hälsa och arbetsoförmåga. Handikappkategorin differentierades utifrån en fysisk, psykisk och social dimension.

De flyktingar som först klassificerades som "difficult cases» inordnades i denna kategori. Deras situation differentierades då utifrån de ovannämnda kriterierna. Denna uppdelning låg till grund för de nya internationella avtalen. I avtalen förband sig vissa länder att ta emot de s.k. handikappade flyktingar inom ramen för speciella kvoter (Hellner 1952, Holborn 1975).

FN:s flyktingkommissarie rekommenderade att de villkor som gällde mottagarlandets medborgare också skulle gälla de särskilt kvoterade flyktingarna.

"With respect to the right to public relief and

6 RA Medicinalstyrelsen, Flyktingsjukvårdsarkiv FI: 99 \& F I 104. FII: 2 -4 Speciell flyktingsjukvård. assistance, refugees are to be accorded the first standard of treatment, i.e., national treatment (article 23). This is a most important provision, as it gives indigent refugees the right to all the benefits of social and medical assistance granted to indigent persons in the modern welfare state". (van Heuven Goedhart 1953s. 297)

I Skandinavien beslutade Danmark, Norge och Sverige att, förutom arbetsföra flyktingar, även ta emot flyktingar som ingick i dessa speciella kvoter. I slutet av 1950-talet hade även andra länder tagit emot kvotflyktingar. ${ }^{7}$ I sammanställningen av dessa kvoter blev beteckningen handikapp den övergripande kategorin.

"Disposition of Handicapped Refugees by Countries of Resettlement, 1959-61

European Countries:

- Denmark: 50 handicapped refugees and their families.

- Norway: 100 handicapped refugees and their families.

- Sweden: 900 refugees, the majority of who were handicapped.

- Belgium: 50 handicapped refugee families from Europe and 250 non-rehabilitable refugees of European origin from the Far East.

- Switzerland: 100 handicapped refugees

7 1... Norway has been outstanding in offering asylum and care to 'hard core' refugees. Blind people, tuberculosis patients, and other physically handicapped refugees, as well as 40 orphans, have been accepted by Norway and resettled with careful attention to their particular needs" (Vernant 1953 p. 377) 
from Europé and the Far East, to be cared for by institutions in the country; in addition, a group totalling 200 persons including rehabilitable handicapped refugees". (Meeting a Challenge, UNHCR, 1961:10 citerad i Holborn 1975 s. 466).

År 1949 tog Sverige det första beslutet om att ta emot ett begränsat antal TBC-sjuka flyktingar och deras anhöriga. ${ }^{8}$ Den första gruppen anlände i början av 1950-talet, dessa följdes av nya, alltid små grupper, under 1950 och 1960-talet. ${ }^{9}$ Det är i administrationen och hanteringen av deras mottagning som vi kan identifiera uppkomsten av en differentierad flyktingverksamhet inom socialtjänsten. I nästa avsnitt beskrivs hur denna verksamhet inordnades i den nationella organisationen. Utgångspunkten var att dessa flyktingar var sjuka och inte kunde försörja sig själva. Deras vård och försörjning skedde inom ramen för de befintliga sjukvårdsinstitutionerna men kostnaderna subventionerades av den internationella flyktingorganisationen IRO (International Refugee Organisation).

\section{Kvoterade flyktingar i Sverige}

Mottagningen av de TBC-sjuka flyktingarna

8 RA Medicinalstyrelsens arkiv. Flyktingsjukvårdsarkiv $\mathrm{F}$ II: P.M. angående omhändertagande av TBC sjuka flyktingar och deras anhöriga. Inrikesdepartementet, 1950.

9 Mellan år 1950-1965 överfördes 15600 flyktingar till Sverige av vilka 13500 var arbetsföra (SOU 1967:18). Bland de icke-arbetsföra fanns de speciellt kvoterade flyktingarna, i första hand TBC-sjuka och deras anhöriga. ska ses mot bakgrund av de specifika nationella kontexterna. I Sverige var 1940- och 1950-talen mycket dynamiska decennier i välfärdsstatens historia. Det var en tid då etablerade kategorier ifrågasattes och gamla åtgärder och lösningar inte längre var självklara. Nu skulle nya kategorier ersätta de gamla och nya strategier skapas för att lösa sociala problem. Nya uppfattningar om hälsa och sociala normer, nya socialpolitiska beslut och ny praxis började förändra relationen mellan myndigheterna och de fattiga och andra tidigare exkluderade grupper. Denna utveckling inbegriper processer som gjorde det möjligt att inkludera nya grupper i den allmänna välfärden. Det är i detta sammanhang vi ska förstå beslutet att ta emot särskilda kvoter flyktingar och inordningen av dessa flyktingar i etablerade organisationer. De flyktingar som inte kunde arbeta blev de sociala myndigheternas ansvar och skulle behandlas utifrån samma regler som gällde den del av den svenska befolkningen som under denna tid började inordnas i kategorin handikappade. Denna började nu utvecklas till en mycket bred kategori som omfattade en mängd skilda grupper. ${ }^{10}$

Under 1940-talet hade Sverige utvecklat en organisation för att ta emot den massiva invandringen av flyktingar som skedde vid krigets slut. ${ }^{11}$ Åtgärderna för att reglera flyktingproblematiken utvecklades med de

10 RA Kommittéarkiv YK 4337, Zigenarutredningen. Expertgruppen för övervägande av åtgärder beträffande vissa zigenare: FIII:2 Betänkande m.m. 1:2 Om organiserad överföring av flyktingar. Se även Montesino 2002.

11 RA Medicinalstyrelsens arkiv. FL II Hälsovårdsbyrån, karantänsfrågor, m.m. 1948. 
resurser som stod till buds. Sverige hade, efter andra världskriget, en välbehållen militär- och sjukvårdsorganisation för att hantera akuta katastrofsituationer, inte minst för att förebygga smittosamma sjukdomar. Den militära organisationen och de kunskaper som fanns inom det medicinska och sociala fältet spelade en central roll för de specifika aktiviteter som utvecklades för att ta emot de tusentals flyktingar som kom till Sverige strax efter kriget (Montesino 2007). Denna reglering skedde $i$ första hand vid rikets gränser. Där var det försvarsmakten som hade ansvaret för registrering och kontroll av de nyanlända men under vistelsen på lägren var det sjukvården och de sociala myndigheterna som hade ansvaret för dem. ${ }^{12}$ Mottagningen av de kvoterade flyktingarna började långt innan de kom till rikets gränser. En svensk delegation åkte till de internationella uppsamlingslägren och valde, i samarbete med de internationella myndigheterna, ut de flyktingar som skulle få resa till Sverige (Thor 2007). Utgångspunkten i urvalet var att flyktingarna skulle vara TBC-sjuka men det fanns även vid detta urval arbetsrelaterade kriterier som styrde den svenska delegationens arbete. De flyktingar som valdes ut bland de TBC-sjuka var huvudsakligen de som betraktades som »rehabiliterbara«.

„Först gjordes en preliminär granskning av samtliga 'fall' och sedan uteslöts dem som av

12 RA Medicinalstyrelsens arkiv. FI c:1 Planering rörande flyktingar 1940. D1:1: 1945 års Flyktingsjukvård. Statens utlänningskommission Sociala Byrån F3:1 Handlingar ang. TBC sjuka barn. F3 A: 2 Handlingar angående barn. journalerna att döma verkade olämpliga. Olämpliga ur medicinisk synpunkt benämndes personer som efter lång sjukhusvistelse visserligen hade utsikt att tillfriskna, men där stor risk för grav invaliditet förefanns. Vidare 'eliminerades' fall där patienten utöver tuberkulosen led av någon annan sjukdom samt fall med 'mentala och psykiska defekter'". (Thor 2007)

Denna strategi kan förstås utifrån de speciella förutsättningar som fanns i Sverige för att ta hand om TBC-sjuka patienter. TBC var en sjukdom som sedan slutet av 1800-talet fått stor uppmärksamhet i myndigheternas hälsoförebyggande arbete. Sjukdomen skördade många liv och var svår att behandla (Andér \& Puranen 1994). Ett halvt sekel senare fanns det resurser och kunskaper för att hantera TBC. Genom förebyggande åtgärder och en bättre levnadsstandard hade myndigheterna kunnat minska antal TBC-sjuka i Sverige (ibid.). I slutet av 1940-talet fanns det en infrastruktur att disponera över. Det fanns lediga platser på sanatorierna, medicinsk kunskap och utrustning för att ta hand om nya patienter. Dessa resurser kunde nu användas för att vårda nyanlända flyktingar. ${ }^{13}$ Bland de flyktingar som hade kommit till Sverige sedan början av 1940-talet fanns det ett hundra tal

13 I populärvetenskapliga skildringar skildras sanatorieverksamheter i olika delar av landet. En del av dessa studier nämner vården av $\mathrm{TBC}$-sjuka flyktingar. Se till exempel Hagström (2000) som beskriver historien kring Lärbro krigssjukhus på Gotland, Helgesson (1993) som skildrar tuberkulosens historia i Blekinge, Ryde (1964) som beskriver samma utveckling i Norrbotten. 
TBC-sjuka. ${ }^{14}$ År 1950 när den första kvoten TBC-sjuka flyktingar anlände, fanns alltså redan erfarenheter av flyktingsjukvård på sanatorierna och i andra sjukvårdsinstitutioner. $^{15}$

Flyktingarna fick resa till Sverige i välorganiserade transporter. Organisationen av deras transport styrdes av regler som gällde hanteringen av epidemiska sjukdomar. ${ }^{16}$ I Sverige fördelades ansvaret mellan Medicinalstyrelsen och Socialstyrelsen: Medicinalstyrelsen ansvarade för de flyktingar som vårdades på sjukvårdsinstitutionerna. ${ }^{17}$ Socialstyrelsen ansvarade för anhöriga som inte kunde försörja sig själva (Berggren 1962, Bååth 1959, 1962). Dit hörde äldre, barn och kvinnor som på grund av familjesituationen inte kunde arbeta. ${ }^{18}$ Flyktingarna inordnades i de kategorier som fattigvården

14 RA Medicinalstyrelsens arkiv. F I : cl Provisoriska TBC-sjukhus.

15 I början av 1940-talet upptäcktes det TBCsjuka bland de finska evakuerade och senare bland de nyanlända baltiska flyktingarna. Dessa flyktingar skickades till speciellt inrättade avdelningar på två psykiatriska sjukhus. (Statens utlänningskommission, F3:1 Sociala byrån \& Medicinalstyrelsens arkiv, F I: c 1).

16 Vid resan togs det speciella smittoskyddsåtgärder (isolering, desinfektion, etc.). Medicinalstyrelsens arkiv Flyktingsjukvårdsarkiv F II: 2 -4 Speciell flyktingsjukvård.

17 Kungl. Brev, 12 maj 1950, angående tbc-sjuka flyktingar jämte anhöriga. Kungl. Brev, 9 juni 1950, angående vissa estlandssvenskar och andra åldringar samt nyanlända varaktigt arbetsoförmögna flyktingar. Kungl. Brev, 27 februari 1959, ang. statlig ersättning för flyktingarnas kostnader

18 Socialstyrelsens arkiv. Socialvårdsbyrån AVIII a Protokoll i flyktingärenden \& AVIII B Protokoll i flyktingärenden. betraktade som hjälpberättigade. Regelverket som styrde deras mottagning var den som gällde den övriga befolkningen.

Utöver kvoteringen av de TBC-sjuka flyktingarna skapade den internationella flyktingorganisationen andra kvoter. Bakgrunden var desamma, det handlade om individer som på uppsamlingslägren också hade definierats som icke-arbetsföra. Många av dem inordnades i kategorin socialt handikappade (Montesino 2002). Detta handikapp kunde beskrivas i relation till utbildning (lägre utbildning eller utbildning som betraktades som svårt att anpassa till nya förhållanden), familjesammansättning (ensamstående kvinnor med barn, stora familjer eller familjer med äldre och /eller sjuka medlemmar), ålder (barn eller äldre), etc. Under 1960-talet beslutade Sverige att även ett begränsat antal »socialt handikappade« flyktingar skulle tas emot i landet.

"Utöver handikapp av fysisk eller psykisk art har även vissa sociala handikapp förekommit. De närmare 300 assyriska och albanska flyktingar som 1967 överfördes till Sverige är i viss utsträckning analfabeter och saknar erfarenhet av arbete och arbetsförhaillanden i ett industrialiserat land "(Ds In 1969:1 s. 111).

Inom socialtjänsten kom denna föreställning kring flyktingskap att styra organisationen över arbetet med flyktingar. På 1970-talet kom även kultur och etnisk bakgrund att representera en speciell problematik.

"Chileflyktingar, öststatsflyktingar, assyrier, ugandier och zigenare är de största grup- 
perna. Många av dessa behöver särskilt stöd $i$ samband med bosättningen, eftersom deras språk, kultur och levnadsmönster skiljer sig mycket från vairt. Många av flyktingarna har bara gått ett par år i skolan... Yrkeskunskaperna passar oftast inte arbetsmarknadens krav. Detta ställer särskilda krav på personella insatser och nya arbetsmetoder inom socialvairden "(Socialnytt 1976 s. 40)

I dessa sammanhang förblev handikappkategorin bestämmande medan den kulturella dimensionen fick en underordnad roll.

"Socialtjänstlagen ger handikappbegreppet en bredare definition än den traditionella. I den nya lagens handikappbegrepp inkluderas även personer med spräksvairigheter, annan kulturell bakgrund och personer med svåra missbruksproblem« (Carlsson 1982 s. 39).

Utgångspunkten för socialtjänstens arbete med flyktingar blev att flyktingskapet utgjorde en speciell form av handikapp. Detta kom på ett avgörande sätt att prägla de verksamheter och institutioner som växte fram för flyktingmottagande. Beslutet att ta emot TBC-sjuka flyktingar år 1949 utgör inledningen på denna historia. Detta formativa moment av flyktingmottagningens institutionalisering har avgörande betydelse för vår förståelse av hur flyktingmottagningen fungerar idag. Detta har inte tidigare uppmärksammats i forskningssammanhang.

\section{Sammanfattning}

I konstruktionen av flyktingkategorin kom föreställningar kring nationell gemenskap och tillhörighet att spela en avgörande roll. I detta sammanhang framstod flyktingskap som en avvikelse. Avvikelsen handlade om flyktingens utanförskap i relation till de etablerade nationella gemenskaperna. De åtgärder som vidtogs efter andra världskriget syftade till att återinlemma flyktingarna till dessa självklara gemenskaper. När repatrieringen och migrationen inte räckte till som lösning skapades speciella flyktingkvoter sorterade utifrån de differentieringar som hade gjorts på uppsamlingslägren för flyktingar. I första hand handlade det om kategorier som relaterade till nya föreställningar kring hälsa/ohälsa. De flyktingar som inte accepterades i migrationskvoterna definierades som handikappade. Flyktingskap associerades till ett handikapp som grundades i medicinska, psykologiska och sociala aspekter. Sverige deltog i ett internationellt migrationsprogram som sökte lösa situationen för de flyktingar som inordnades i handikappkategorin. Deras ankomst ledde till framväxten av en flyktingverksamhet inom socialtjänsten. Dessa flyktingar inordnades i den etablerade verksamhet som gällde andra grupper som uppfattades som oförmögna att försörja sig själva. Detta kom att prägla de sociala myndigheternas hantering av flyktingar. För att förstå socialtjänstens arbete med flyktingar idag kan inte denna bakgrund förbises. 


\section{Litteratur}

Andér, Lars \& Puranen, Bi (1994) Konung OskarII:s jubileumsfond och tuberkuloskampen. Nordisk Medicinhistorisk Årsbok, Supplementum XIV.

Arendt, Hannah (1966) The Origins of Totalitarianism. New York: Harcourt.

Bashford, Alison (2005) Imperial Hygiene. A Critical History of Colonialism, Nationalism and Public Health. Australien: Palgrave Macmillan.

Berggren, Ali (1962) „Socialvårdsbyrån - bakgrund, verksamhet och problem". I Sociala Meddelanden nr 7-8, s. 593-604.

Bååth, Inga (1959) „Ett led I Sveriges Fortsatta humanitära flyktingpolitik: Socialvård åt flyktingar». Sociala Meddelanden $\mathrm{nr}$ 3-4, s. 226-233.

Bååth, Inga (1962) „Flyktingar». Sociala Meddelanden nr 6-7, s. 627-634.

Carlsson, Rolf (1982) "Socialtjänsten och de handikappade" Socialnytt nr 1, s. 38-42.

Ds In 1969:1 Om organiserad överföring av vissa zigenare. Stockholm: Departementserie.

Grossmann, Atina (2002) "Victims, Villains, and Survivors: Gendered Perceptions and Selfperceptions of Jewish Displaced Persons in Occupied Postwar Germany". Journal of the History of Sexuality Vol 11, nr. 1/2, s. 291-318.

Hagström, Svante (2000) Lärbro Krigssjukhus. Gotlands Militärkommando.

Helgesson, Michael (1993) Pengarna och vården. Om kampen mot tuberkulosen i Blekinge. Karlskrona: Blekinge läns förening mot hjärt- och lungsjukdomar.

Hellner, Kerstin (1952) De landsflyktiga och Sverige. Stockholm: Albert Bonniers Förlag.

Holborn, Louise W. (1975) Refugees a Problem of Our Time. The Work of The United Nations High Commissioner for Refugees. Vol. I. Metuchen N.J.

Immergut, Ellen (1992) »The rules of the game: The logic of health policy-making in France, Switzerland and Sweden". IS. Steinmo, K. Thélen \& F. Longstreth (red.) Structuring Politics: Historical Institutionalism in Comparative Analysis.
Cambridge: Cambridge University Press.

Kerz J., Werner M. \& Wesser E. (1995) Vad vet vi om rehabilitering?: Svensk rehabiliteringsforskning. Lund: Boxbok förlag.

Lecours, André (2005) New Institutionalism: Theory and Analysis. Toronto: University of Toronto Press, Toronto.

Lomfors, Ingrid (2005) Blind fläck: minne och glömska kring svenska Röda korsets hjälpinsats $i$ Nazityskland. Stockholm: Atlantis.

Malkki, Liisa (1992) „National Geographic: The Rooting of Peoples and the Territorialisation of National Identity Among Scholars and Refugees", Cultural Anthropology vol.7, nr 1, s. 22-44

Malkki, Liisa (1995) „Refugee and exile: From 'Refugee Studies' to the National Order of Things", Annual Reviews in Anthropology nr 24, s. 495-523.

Malkki, Liisa (1996) „Speechless Emisaries: Refugees, Humanitariamism, and Deshistoricization", Cultural Anthropology vol.11, nr 3, s. 377-404.

Montesino, Norma (2002) Zigenarfrågan, intervention och romantik. Lund: Lund Dissertation in Social Work, Socialhögskolan.

Montesino, Norma (2007) „Flyktingmottagning en fråga kring hälsa och arbete». I Jan Ekberg (red.) Sveriges mottagning av flyktingar - några exempel. Växjö: Växjö Universitet.

Nauman, Christian (1866) "Om främlingars asylrätt i Sverige", Tidskrift för Lagstiftning, Lagskipning och Förvaltning, Stockholm.

Pinegar, Warren A. (1960) »The Refugee Situation in Europe", The Social and Economic Aspects of Refugee Integration, European Seminar, Report Stockholm.

Proudfoot, Malcolm J. (1956) European Refugees: 1939-52. A Study in Forced Population Movement. London: Faber and Faber LTD.

Ryde, Carl (1964) Kampen mot en folksjukdom, en skrift om tuberkulosvården i Norrbottens Län 1913-1963. Norrbottens Museum.

Slatt, Vincent E. (2001) „Nowhere to go: Displaced 
Person in Post-V-E-Day Germany", The Historian, s. 275-293.

Socialnytt (1976) "Socialservice och omvårdnad", Social nytt, Petita nummer s. 39-43.

SOU 1967:18 Invandringen, problematik och handläggning.

Stoessinger, John G. (1956) The Refugee and the World Community. Minneapolis: The University of Minnesota Press.

Thor, Malin (2007) »Det är billigare att bota ett TBC-fall än att uppfostra en svensk. Den svenska kvotflyktingmottagningen av ickearbetsföra flyktingar 1950 -1955 «. I Jan Ekberg (red.) Sveriges mottagning av flyktingar - några exempel. Växjö: Växjö Universitet.

Tilly, Charles (1998) Durable Inequality. Berkeley: University of California Press.

Tilly, Charles (2005) Identities, Boundaries \& Social Ties. London: Paradigm Publishers.

Van Heuven Goedhart, G.J. (1953) »The Problem of Refugees", Académie De Droit International, Recueil Des Cours, Collected Courses 1953 vol 1 nr 82, s. $265-369$.

Vernant, Jacques (1953) The Refugee in the Post War World. London: George Allen and Unwin Ltd.

Weindling, Paul (2006) „Belsinitis': Liberating Belsen, It's hospitals, UNRRA, and Selection for Re-emigration 1945-1948", Science in Context vol.19 nr 3, s. 401- 418.

Woodbridge, George (1950) UNRRA The History of the United Nations and Rehabilitation Administration. Vol. 1\& 2. New York: Columbia University Press.

Zalashik, Rakefet \& Davidovitch, Nadav (2006) „Measuring Adaptability: Psychological Examinations of Jewish Detainees in Cyprus Internment Camps", Science in Context vol.19 nr3, s. 419-441.

\section{Övriga källor}

\author{
Riksarkivet (RA), Stockholm \\ Kommittéarkiv \\ Expertgruppen för övervägande av åtgärder beträf- \\ fande vissa zigenare, YK 4337 \\ Om organiserad överföring av flyktingar, FIII:2 \\ Medicinalstyrelsens arkiv \\ 1945 års flyktingsjukvård, D 1:1 \\ Planering rörande flyktingar, FI C:1 \\ Hälsovårdsbyrån, karantänsfrågor m.m. 1948 -, FL II \\ Flyktingsjukvårdsarkiv: \\ Sjukjournaler, F I:99 - F I: 104 \\ Speciell flyktingsjukvård, F II: 2-4 \\ Socialstyrelsens arkiv \\ Socialvårdsbyrån
}

Protokoll i flyktingärenden, AVIII a

Protokoll i flyktingärenden, AVIIIb

Statens utlänningskommission

Sociala Byrån

Handlingar ang. TBC-sjuka barn, F3:1

Handlingar ang. barn, F3 A 2

Kungl. Brev

Kungl. Brev, 12 maj 1950, angående tbc-sjuka flyktingar jämte anhöriga.

Kungl. Brev, 9 juni 1950, angående vissa estlandssvenskar och andra åldringar samt nyanlända varaktigt arbetsoförmögna flyktingar.

Kungl. Brev, 27 februari 1959, ang. statlig ersättning för flyktingarnas kostnader 


\section{Summary}

\section{Refugeeness, a kind of disability}

In this article I describe the context in which some refugees were classified as handicapped after the Second World War and how this influenced the Swedish social authorities' handling of refugees during the 1940s and 1950s. In the 1940s the international organisations responsible for refugees demanded a response from the international community to address the difficult situation created by the very large refugee population. Many of the refugees were in refugee camps, while others had to make a living without documents that recognized them as part of the local or national population. The international community, in cooperation with nongovernmental organisations, created an infrastructure to facilitate the return of the refugees to their countries of origin or emigration to countries that promoted immigration. However, at the end of the decade the authorities had to recognize that these measures were not enough to solve the refugee situation. In search of an alternative policy, it was necessary to develop a common understanding or definition of who was a refugee. This resulted in a new, more universal definition of the refugee category. The refugees were now identified as a special category of migrant, a person without legal protection, someone who lacked the protection of the nation state, a person without territorial belonging, i.e. lacking the precondition for being considered part of the more general and inclusive population category. The refugee situation transformed the person into an individual with a special kind of "disability", an alien without a community where he/she could demand protection. The measures to solve the refugee question were to return the refugee to what was conceived as a normal state of things. The first measures (repatriation, migration) did not solve the problem. The traditional immigration countries (USA, Australia and Canada) selected higher-skilled and young people in good health (especially men). The selective migration policies left many refugees in the European countries, people who did not have any chance of being accepted as members of the national communities because they were not considered able to work. These refugees were called "the hard core or difficult cases or residual cases", comprising the old, the sick, the disabled, the children and often the women: the traditional categories of welfare policy.

In search of new solutions the qualities that defined an individual as a refugee were differentiated. The disability that identifies a refugee as refugee implied additional dimensions: a lack of health was defined as a physical or mental handicap, while lack of economical resources or lack of education, etc. was seen as social handicap. On this basis the international community, in cooperation with different nation states, promoted special programmes for these refugees. Sweden was one of several countries that accepted a selected and limited number of these so called 
handicapped refugees. The first selected refugees in these quotas had tuberculosis and needed special care. The health and social authorities provided the medical and economic assistance. The refugees were interned in sanatoriums or other institu- tions. During this time the social authorities organised the future of these people. They would be assisted in the same way as Swedes who could not be integrated on the labour market, people who were defined as handicapped. 